The University of Southern Mississippi

The Aquila Digital Community

Honors Theses

Honors College

Spring 5-2015

\title{
The Effects of Aging on Auditory Duration Discrimination
}

Rachael N. Luckett

University of Southern Mississippi

Follow this and additional works at: https://aquila.usm.edu/honors_theses

Part of the Speech Pathology and Audiology Commons

\section{Recommended Citation}

Luckett, Rachael N., "The Effects of Aging on Auditory Duration Discrimination" (2015). Honors Theses. 302.

https://aquila.usm.edu/honors_theses/302

This Honors College Thesis is brought to you for free and open access by the Honors College at The Aquila Digital Community. It has been accepted for inclusion in Honors Theses by an authorized administrator of The Aquila Digital Community. For more information, please contact Joshua.Cromwell@usm.edu. 
The University of Southern Mississippi

The Effects of Aging on Auditory Duration Discrimination

by

Rachael Luckett

A Thesis
Submitted to the Honors College of
The University of Southern Mississippi
in Partial Fulfillment
of the Requirements for the Degree of
Bachelor of Arts
in the Department of Speech and Hearing Sciences

May 2015 


\section{Approved by}

Edward L. Goshorn, Ph.D., Thesis Adviser Associate Professor of Audiology

Steven J. Cloud, Ph.D., Chair

Department of Speech and Hearing Sciences

Ellen Weinauer, Ph. D., Dean

Honors College 


\begin{abstract}
The goal of this study is to identify how auditory duration discrimination ability varies across age groups by using an unbiased stimulus such as a music tone. This will be accomplished by conducting a quantitative study testing duration discrimination skills in young and elderly adults. Their confidence ratings per response will also be included along with their discrimination results. The author will generate data that compare the duration discrimination abilities of young versus elderly adults. The null hypothesis is that there is no difference in duration discrimination between elderly and young adults.
\end{abstract}

Key Terms: music, confidence, aging, discrimination, auditory processing, duration 


\section{Acknowledgments}

First, I want to thank God for opening my heart to this challenge. I would not have the patience and understanding that I have now without his love and guidance. I would like to thank my thesis adviser, Dr. Goshorn, for always being patient with me and for teaching me how to be successful in my field. Thank you to all my brave volunteers who helped contribute to my data. I want to thank my family for trusting me at all times, even when I was too overwhelmed to explain everything. Most of all, thank you to my friends for listening every time I needed to vent about all the hard work that was needed to make this thesis possible and for being my rock. 


\section{Table of Contents}

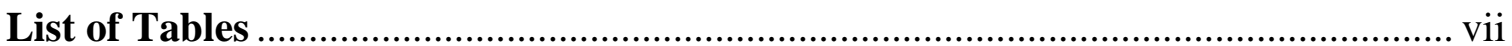

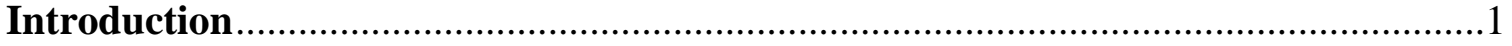

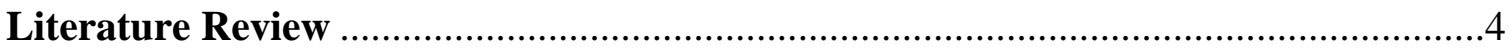

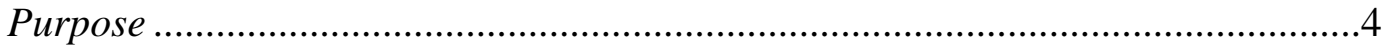

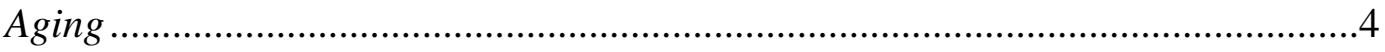

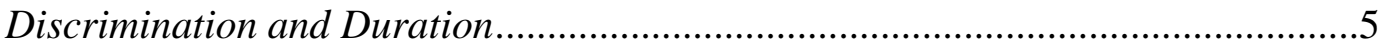

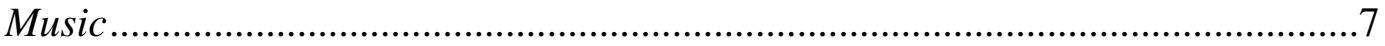

Confidence Ratings ....................................................................................

Research Question .....................................................................................9

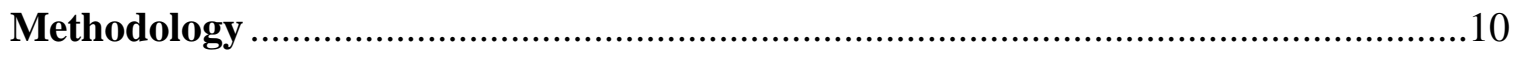

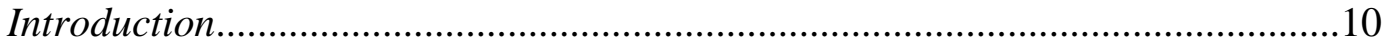

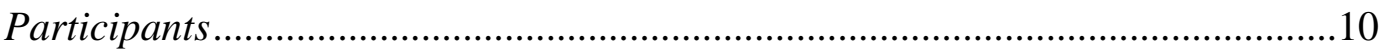

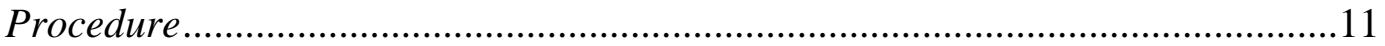

Data Collection ..........................................................................................12

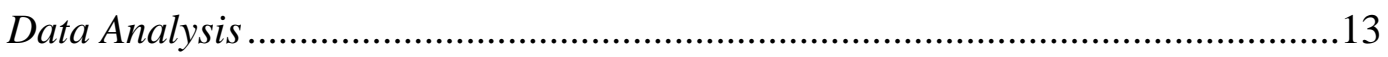

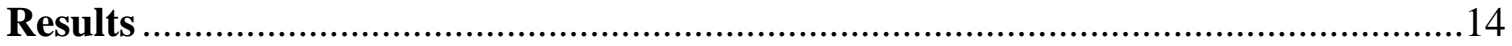

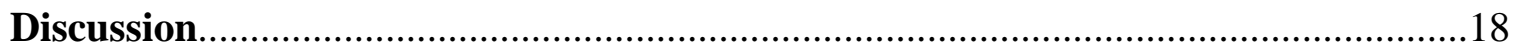

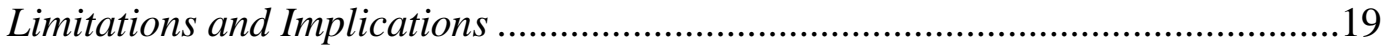

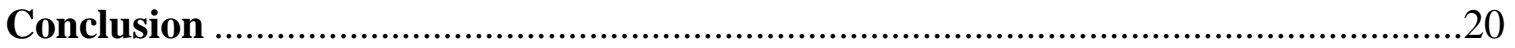

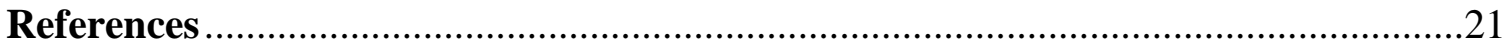

Appendix 
List of Tables

Table 1: Tests of Between Subjects Effects......................................................14

Table 2: Descriptive Statistics of Percent Correct in Correlation to Age and

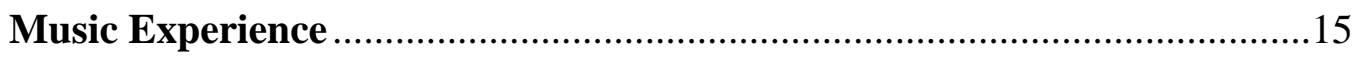

Table 3: Descriptive Statistics of Percent Correct in Correlation to Age and Sex ....16

Table 4: Quantity of Confidence Rating Categories for Younger and Elderly

Participants. .16 


\section{Introduction}

With aging comes the natural loss of body functions. One of these functions is hearing. As humans age, average hearing capabilities, such as auditory discrimination, are diminished. Auditory discrimination is the ability to distinguish the difference between two sound stimuli. The discriminated signals usually are speech, but they may be non-speech signals, such as tones or musical signals. The purpose of the present study is to determine if duration discrimination of a musical note varies across age groups.

There are many events in human life that can cause hearing loss, such as noise exposure, medical disorders and treatment, drugs, and more. Sociocusis, or "wear and tear," is a term that encompasses all the above to lose hearing ability (Glorig \& Nixon, 1962). Presbycusis is a term associated with age-related loss of hearing. The four types of presbycusis hearing loss are sensory, neural, metabolic, and mechanical or cochlearconductive. Presbycusis affects the peripheral, central auditory, and central nervous system activity and can alter sound discrimination (CHABA, 1988). Plomp found that with each interval of hearing loss a corresponding interval of speech understanding also is lost (as cited in CHABA, 1988). Presbycusis may also cause poor performance on auditory tests, including word-recognition tests (Berkowitz \& Hochberg, 1971). An auditory discrimination task typically consists of differences in signal loudness, pitch, or duration. The signal may be speech or nonspeech, such as a pure tone or a musical note.

The increase in the geriatric population has resulted in an increase in the population of hearing impaired individuals (CHABA, 1988). It is common for older adults to be unable to follow conversation spoken at average intensity levels (CHABA, 1988). 
Discrimination is the ability to distinguish differences among sounds, usually by categorizing a pair of sounds as 'same' or 'different' (McMahon, 1979). Auditory discrimination abilities are linked to the central auditory pathway. The processing centers along this pathway are directly affected by the deterioration associated with aging (CHABA, 1988). Discrimination is an ability that is independent of other parameters; this has been proven for duration discrimination as well (Abel, 1972). A decrease in duration discrimination may be tied to a degeneration of temporal processing in the central auditory system (Freigang, Schmidt, Wagner, Eckardt, Steinhagen-Thiessen, Ernst, \& Rübsamen, 2011). An age-related decline in temporal processing in the brainstem and cortical auditory areas may be revealed by an increase of just noticeable differences (JNDs) for duration discrimination (Freigang et al., 2011). Given the association between discrimination tasks and the central auditory pathway, assessing the ability to discriminate sound duration should be added to the central auditory processing test battery. This addition may improve the validity of Central Auditory Processing Disorder (CAPD) tests.

Most discrimination tests use speech stimuli. Using a speech stimulus introduces variables such as the type of voice used, how the message is sent to the participant, the diction of the message, the context of the message, the language of the message, the participant's first language, and the speech intelligibility of the speaker.

Duration discrimination is used as a part of speech perception to perceive differences in the stressing of speech signals (Peter, McArthur, \& Thompson, 2012). This type of discrimination "relies on central auditory networks which comprise brainstem nuclei and subcortical and cortical networks," and it depends on the "activation of 
frontoparietal areas” (Freigang, et al., 2011, p. 9). The ability to discriminate duration is important to speech because it allows one to sense stress in syllables.

Duration is also important in music because it is used to emphasize certain notes, and it divides the musical flow into "meaningful segments" (Peter et al., 2012, p. 1590). Variations in music and speech durations are processed similarly, but music processing occurs primarily in the right hemisphere of the brain, and speech is processed in the left hemisphere (Peter, et al., 2012). Music is universal. It is not specific to any language, and it does not require any level of intelligence to perceive it. Using a musical note from a basic instrument like a piano allows the participant to focus on the signal instead of also trying to understand the language of a speech stimulus. The ability of a listener to discriminate intensity, frequency, spectral shape, or duration of musical notes can help to explain the listener's ability to discriminate in a normal communication environment (Grassi \& Borella, 2013). A music stimulus provides a unique but valid way to test duration discrimination. Also, a music stimulus could provide additional cues to a listener that may facilitate discrimination.

Duration discrimination contributes to other functions or abilities that humans possess. These other affected functions are reliant on the ability to discriminate sound durations. The accuracy in testing discrimination is of the utmost importance; therefore, it should not be biased and should consist of various stimuli, including music tones. This study could help identify the age at which duration discrimination ability begins to diminish. Can elderly subjects judge the duration of a musical tone as precisely as younger subjects? 


\section{Literature Review}

\section{Purpose}

Testing auditory duration discrimination using a musical tone will add a new stimulus to the assessment battery of tests.

\section{Aging}

Adolescence triggers the beginning of hearing sensitivity loss, starting with the high frequencies. This verifies that aging is a factor in hearing loss since most adolescents have not been exposed to enough noise to affect the auditory system. Most elderly adults have very poor hearing in the high frequencies, with major hearing shifts occurring between the ages of 30 and 65 (CHABA, 1988).

Declines in cognitive abilities correlate well with declines in duration discrimination associated with increased age. Cognitive functions affected include working memory, processing speed, and everyday reading and problem solving (Grassi \& Borella, 2013). Grassi and Borella observed the auditory temporal ability of duration discrimination in relation to cognitive abilities in older adults, and they found that auditory abilities are related to cognitive functions. Using synthesized tones as the stimulus, the participants were Italian volunteers. There was a very distinct difference across age in their results. The oldest group of adults was substantially slower with cognitive functioning than younger adults. Duration discrimination was a factor that contributed to processing speed (Grassi \& Borella, 2013). Overall, the auditory nervous system shows more deterioration in older adults (CHABA, 1988). 


\section{Discrimination and Duration}

Discrimination may be assessed using several factors. For example, discrimination is a factor in reading readiness and reading achievement (McMahon, 1979). In a study conducted by Abel (1972), discrimination ability was tested between two durations. He controlled all parameters of the Gaussian noise bursts except duration. Some stimulus parameters may cue small differences in duration to the listener. Abel used a standard 500 msec interstimulus interval (ISI) between two noise bursts in each pair. Duration discrimination testing has taken a variety of forms. The present study will attempt to eliminate other factors, such as speech understanding and comprehension, by using a nonspeech signal.

A very reliable study focused on assessing the auditory duration discrimination ability specifically in elderly adults (Freigang et al., 2011). The authors cited three hypotheses for deterioration of speech perception due to age: the peripheral hypothesis, the central auditory hypothesis, and the cognitive hypothesis. This study assessed different age groups using JNDs of tone bursts presented monaurally (Freigang et al., 2011). These authors confirmed other previously cited studies by showing a clear change of hearing sensitivity with age (Freigang et al., 2011). They stated that "thresholds for signal duration discrimination were strongly age-dependent” (Freigang et al., 2011, p. 5), especially for monaural thresholds. The older adults had an elevated threshold compared to younger adults which could be due to a "reduction of the dynamics of interaural processing” (Freigang et al., 2011, p. 9). This test was originally designed to evaluate central auditory processing, and it contained limited bias or demand on intelligence. In order to test the physiological aging of the auditory system, more thorough and accurate 
assessments of “medical, genetic, social, and audiological factors” will need to be written, standardized, and put in place (CHABA, 1988, p. 885).

Because current auditory tests frequently use speech signals, this can create a bias for those who can understand the speech signal. Depending on how the words of the speech signal are edited, sometimes people can predict what word or sound is going to come next because they have reached a certain level of speech intelligence (CHABA, 1988). Suggestions have previously been made to use more than just single words and tones to test cognitive and peripheral processes (CHABA, 1988).

Some auditory abilities are better assessed using nonspeech signals. Noise bursts and pure tones have been used as stimuli, but a music tone nonspeech signal has not been used in a test for duration discrimination.

Nonspeech signals consisting of pure tones, such as a sine wave of constant amplitude and frequency, do not provide any additional cues across time. For music tones, the waveform fundamental frequency is the initial strike of the note on the instrument, and the different harmonics will immediately follow. The principal pitch of a tone is predicted by its frequency, and this pitch can vary up to a semitone in a music performance (Etchemendy, 2014). When striking the same note, the amplitude may vary depending on the intensity of the strike, but the harmonics should follow a similar pattern as time progresses. When perceiving a musical tone, a person is not required to possess any previous knowledge of speech and has no expectations of what to hear next from the signal (CHABA, 1988). 


\section{Music}

Guclu, Sevinc, and Canbeyli (2011) used two durations of 0.5 sec and 3.0 sec which were altered between 100-900 msec and 1-5 sec, respectfully, to assess discrimination ability with people of various musical skills (p. 679). Before this study was conducted, it was predicted that musicians would perform better in temporal processing and frequency-related processing in music and that they would auditorily discriminate better than nonmusicians (Guclu et al., 2011). The study focused on five factors: musicians versus nonmusicians, participants' sex, sensory input, modality, and standard duration. The study proved correct in that musicians discriminated better than nonmusicians (Guclu et al., 2011). Even though the results only showed a 10\% better discrimination ability for musicians, the difference apparently affects the way musicians time tasks in music (Guclu et al., 2011). After completing more formal musical training than nonmusicians, musicians can also synchronize durations more clearly (Guclu et al., 2011). Although Guclu was comparing the ability of musicians and nonmusicians, he did not use music as the stimulus; instead he used a noise burst of sinusoidal waves as the auditory stimulus (2011).

An experiment on school-aged children evaluated auditory perception and discrimination with musical pure tones from a piano (McMahon, 1979). Assessing music duration discrimination across different age groups, however, has not been done. When choosing a music stimulus for this study, a common frequency note from the piano was selected because it seems to be the most basic instrument for playing or learning music. No auditory discrimination test has been found that uses just one highly controlled music 
note as the stimulus. The only music discrimination tests that were found used sequences of notes to test memory more so than discrimination (White, 1954).

On the same note, musical training involves the discrimination of pitch and temporal acuity (Koelsch, 2012). The primary auditory cortex is involved in auditory processing such as detecting small frequency differences, storing short-term auditory information, and in discrimination (Koelsch, 2012). Tests that use a music stimulus potentially influence treatment strategies for auditory disorders and in the way discrimination is tested and measured in CAPD assessments.

\section{Confidence Ratings}

Confidence rating methods are conducted based on lax to strict criteria that the participant possesses confidence in his or her decision and shows it by rating confidence on a yes-no basis (Gelfand, 1998). Using a yes/no method of “yes- they are the same"/"no- they are not the same” responses sets up the participant for success due to the low level of difficulty of this testing style (Gelfand, 1998, p. 278). To maintain the cooperation and attention of participants, one should allow a reasonable amount of time for responding to each stimulus which reduces frustration or rushing to find an answer (CHABA, 1988). Attention is lost, especially by elderly adults, if the test time is too long (Freigang et al., 2011). This attentional aspect also relies on cognitive abilities which decrease with age (Freigang et al., 2011).

In the article Speech Understanding and Aging, a research recommendation was made to explore the connection between a listener's attitude regarding his or her hearing impairment and its effect on communication success (CHABA, 1988). A person's attitude toward speech and his or her hearing impairment will indeed affect the way he or 
she communicates (CHABA, 1988). Frustration can result from persistent failure, and this can affect how aggressively a person listens and responds (CHABA, 1988). Regardless of the participants' responses, it is important to measure the accuracy of responses.

Elderly adults tend to be less accurate in judging their responses, and they can have communication problems due to errors in perception and a generalized lack of awareness of errant perception (CHABA, 1988). Cyr and Anderson (n.d) were among the first to test the error awareness in elderly adults. They found that elderly adults could correct error awareness as young adults, but overconfidence in accuracy occurred less often in young adults, and it was found more on multiple choice tests than on recall tasks (Cyr \& Anderson, n.d.).

\section{Research Question}

Speech is one of the most important signals a person can hear (CHABA, 1988). With loss of hearing sensitivity comes greater difficulty in speech understanding (CHABA, 1988). Accurately assessing our ability to hear should be the highest priority of speech-language pathologists and audiologists. In order to be as accurate as possible, different methods and stimuli should be tried and evaluated to identify optimal stimuli, including nonspeech signals such as music. Are elderly subjects able to judge the duration of a musical tone as precisely as younger subjects? The following section will describe the methods used to evaluate the use of a musical tone in a duration discrimination study in young and elderly adults. 


\section{Methodology}

\section{Introduction}

The goal of this study is to identify how auditory duration discrimination ability varies across age groups by using an unbiased stimulus such as a music tone. This will be accomplished by conducting a quantitative study testing duration discrimination skills in young and elderly adults. Their confidence ratings per response will also be included along with their discrimination results. The author will generate data that compare the duration discrimination abilities of young versus elderly adults. The null hypothesis is that there is no difference in duration discrimination between elderly and young adults.

\section{Participants}

The participants consisted of two groups, young adults and elderly adults. The young adult group contained 30 individuals between the ages of 18 and 30, and the elderly adult group contained 32 individuals between the ages of 65 and 90 . An attempt was made to keep the ratio of male to female participants equal. Participants were recruited from the Hattiesburg community and from the University of Southern Mississippi campus. Research announcements also were sent to various churches in Hattiesburg and to campus mailouts.

Each participant completed a questionnaire of basic demographic information which asked for the highest level of education received, how many and which languages they spoke, and whether they had any musical background or training. They also were asked to provide background health information, related to any diagnosed or undiagnosed hearing impairments, hearing aids, processing disorders, or any other health problems. 


\section{Procedure}

After providing written and verbal instructions, four practice trials were completed to introduce the stimuli test parameters. All participants received the same auditory discrimination test under the same conditions. This study was conducted in a sound-treated room in the USM Audiology Clinic. This kept the ambient noise levels the same for each participant. Each participant sat in a chair in the same location and faced the same direction. Each stimulus was played through an insert earphone to the right ear.

By controlling the parameters and other qualities of the stimuli during presentation, the only change in the stimuli occurred in the duration of the second tone in the pair for pairs that were different. While the first note always served as a control duration of 1 second, the second tone was adjusted by 100 msec or 200 msec resulting in a 900 msec or 800 msec duration, respectively. There were 100 pairs of music notes presented, half of equal duration and half of unequal duration.

Only one recording was used. It was a recording of the piano note $\mathrm{G} ¥ 4$ with a fundamental frequency of $422 \mathrm{~Hz}$. A piano note was used because this test was unbiased in comparison to a word test for those who cannot understand speech. A tone also provides a less complex stimulus. The fundamental frequency of the note was $422 \mathrm{~Hz}$, with harmonics at $844 \mathrm{~Hz}, 1270 \mathrm{~Hz}, 1714 \mathrm{~Hz}, 2140 \mathrm{~Hz}, 2600 \mathrm{~Hz}$, and $3034 \mathrm{~Hz}$. These measurements were from the piano note $\mathrm{G} \sharp 4$ that was used for the recording and were documented by Dr. Edward Goshorn. All stimuli were derived from the original recording of this note. The presentation amplitude of the stimuli was $50 \mathrm{~dB}$ HL for each pair, unless the researcher was presented with an extreme case of hearing loss in the right ear. In this case of extreme hearing loss, the participant was still tested for any significant 
influences in the study's results. To avoid temporal masking and to not tax the auditory memory too much, an interstimulus interval (ISI) of 500 msec will be inserted between the tones in each pair; this is a conventional amount of time to space between two signals. The editing and recording of the stimuli was completed using Sound Forge (Version 9).

The only variable in this study was the duration of the second tone in a pair of tones. The stimuli were a pair of musical notes that are either equal or unequal in duration. The test consisted of 100 sound pairs (50 same, 50 different), and the instructor verbally delivered full, clear instructions. The participant's task was to designate which pairs are the same and which are different by saying "same" or "different" after each pair is presented, and the instructor recorded all answers. After discriminating each sound pair, the participant rated how confident he or she was in the chosen answer by using a confidence rating of "yes" or "no". The instructor recorded this rating along with the response. The participant heard each pair once, and they were given four seconds to respond. The test lasted approximately 30 minutes.

\section{Data Collection}

Once the IRB approved the study, a testing schedule was made around the USM Audiology Clinic's schedule to use their adult sound-treated room. Each week for five weeks, time slots were set up to test each participant. Dr. Edward Goshorn assisted in the study.

Quantitative data was collected for the number of correct and incorrect discrimination responses from the participants and for the number of awareness of accurate responses derived from participants’ confidence ratings. This data was analyzed 
for each group. The data was also analyzed to see how it varies by sex and by musical background.

\section{Data Analysis}

The data collected was analyzed in a way to identify differences between age groups in the ability to discriminate differences in duration. The research hypothesis was that due to diminished auditory discrimination ability associated with aging, the elderly will do more poorly. This will be described in the Results section. 


\section{Results}

The SPSS statistical program and ANOVA software were used to configure all data results from a master Excel sheet of individual participant results. The data was structured to compare the results of the elderly adult group and the young adult group. The results focused on the study's purpose of identifying the ability of duration discrimination between young and elderly adults.

The study announcements produced a total of 62 participants. The data for the elderly adult group was collected from 32 participants, including 18 females and 14 males. The elderly group had an age range of 59-86 and an average age of 71.8. The elderly group had a pure tone average (PTA) range of 13-48 dBHL and a PTA average of $26 \mathrm{dBHL}$. The data for the young adult group was collected from 30 participants, including 15 females and 15 males. The young group had an age range of 18-29 and an average age of 22.1. The young group had a PTA range of 2-27 $\mathrm{dBHL}$ and a PTA average of $9.9 \mathrm{dBHL}$. Because of the difference in PTA, the PTA data was treated as a covariate.

Table 1-- Tests of Between Subjects Effects

\begin{tabular}{|l|c|c|c|c|c|}
\hline \multicolumn{1}{|c|}{ Source } & Type III Sum of Squares & Df & Mean Square & F & Sig. \\
\hline Corrected Model & $3839.339^{\mathrm{a}}$ & 4 & 959.835 & 5.890 & .000 \\
\hline Intercept & 27056.187 & 1 & 27056.187 & 166.025 & .000 \\
\hline PTA & 189.315 & 1 & 189.315 & 1.162 & .286 \\
\hline AGE_CODE & 1407.081 & 1 & 1407.081 & 8.634 & .005 \\
\hline MUS_CODE & 424.911 & 1 & 424.911 & 2.607 & .112 \\
\hline $\begin{array}{l}\text { AGE_CODE* } \\
\text { MUS_CODE }\end{array}$ & 497.249 & 1 & 497.297 & 3.051 & .086 \\
\hline Error & 9289.000 & 57 & 162.965 & & \\
\hline Total & 257069.000 & 62 & & & \\
\hline Corrected Total & 13128.339 & 61 & & & \\
\hline
\end{tabular}


Table 1 shows the ANOVA results for the overall effects of all variables of interest. Age was the major contributor to percent correct with the young group scoring higher than the elderly group. The PTA was not a significant contributor to percent correct. Age and music experience did not show a two-way interaction.

Table 2-- Descriptive Statistics of Percent Correct in Correlation to Age and Music Experience

\begin{tabular}{|l|c|c|c|}
\hline AGE + MUS CODE & Mean & Std. Deviation & N \\
\hline $\begin{array}{l}\text { Young + No Music } \\
\text { Exp. }\end{array}$ & 61.00 & 14.832 & 9 \\
\hline Young + Music Exp. & 73.19 & 11.378 & 21 \\
\hline Young Total & 69.53 & 13.500 & 30 \\
\hline $\begin{array}{l}\text { Elderly + No Music } \\
\text { Exp. }\end{array}$ & 57.00 & 11.343 & 19 \\
\hline Elderly + Music Exp. & 55.38 & 15.311 & 13 \\
\hline Elderly Total & 56.34 & 12.888 & 32 \\
\hline All + No Music Exp. & 58.29 & 12.433 & 28 \\
\hline All + Music Exp. & 66.38 & 15.519 & 34 \\
\hline All Total & 62.73 & 14.670 & 62 \\
\hline
\end{tabular}

Table 2 shows the mean and standard deviation data for each factor. A trend was observed that music experience was effective for young participants but not for the elderly. For young participants, music experience yielded significantly higher scores. For older participants, music experience did not improve scores. Although music experience improved scores for younger participants, the average of all participants with music experience did not show any improvement of scores compared to the average of all participants with no musical experience. 
Table 3-- Descriptive Statistics of Percent Correct in Correlation to Age and Sex

\begin{tabular}{|l|c|c|}
\hline \multicolumn{1}{|c|}{ AGE + SEX } & Mean & Std. Deviation \\
\hline Young female & 68.20 & 12.370 \\
\hline Young male & 70.87 & 14.856 \\
\hline Young total & 69.53 & 13.500 \\
\hline Elderly female & 55.67 & 10.754 \\
\hline Elderly male & 57.21 & 15.602 \\
\hline Elderly total & 56.34 & 12.888 \\
\hline All females & 61.36 & 12.983 \\
\hline All males & 64.28 & 16.479 \\
\hline All total & 62.73 & 14.670 \\
\hline
\end{tabular}

Table 3 shows the relationship between sex and age for mean percent correct and standard deviation. The total mean for percent correct of all participants was 62.73 . The total mean for the young group was 69.53. The total mean for the elderly group was 56.34. The total mean for all females was 61.36, and the total mean for all males was 64.28. Although the males scored 2-3\% higher in each age group and overall, sex did not have a significant effect on the ability to discriminate duration of a music tone.

Table 4-- Quantity of Confidence Rating Categories for Younger and Elderly Participants

\begin{tabular}{|l|c|c|c|c|}
\hline AGE & HIT & MISS & FA & CORREJ \\
\hline Young adults & 51.733 & 17.8 & 19.267 & 11.2 \\
\hline Elderly adults & 45.313 & 11.031 & 35.656 & 8 \\
\hline
\end{tabular}

Table 4 shows the relationship between the confidence rating categories and frequency of responses across young and elderly participants. The following were the 
confidence rating categories: hit (correct response and confident), miss (correct response but not confident), false alarm (wrong response and confident), and correct rejection (wrong response but not confident). Based on the confidence categories, the young group was confident more often when the correct response was given. The elderly group was confident more often when the given response was judged to be accurate but in fact it was wrong. 


\section{Discussion}

The purpose of this study was to measure how duration discrimination performance and confidence ratings vary across age groups when using a music note as the stimulus. The results were analyzed according to the null hypothesis of the study.

The results proved significant effects for this study. The largest significant effect is shown in the relationship between age and mean percent correct. Young participants scored over 13\% higher than elderly participants. This finding is consistent with previous studies that show decreased duration discrimination ability as a result of increased age (Freigang et al., 2011; Grassi \& Borella, 2013; CHABA, 1988). This diminished ability is due to the deterioration of the auditory nervous system and auditory temporal ability.

The confidence ratings also were different for the two groups. The data show significant effects due to the age of the participants, such as the increased number of false alarms for the elderly group. This finding also supports earlier studies that find elderly adults to have less accuracy in judging their responses and lack of error awareness (CHABA, 1988; Cyr \& Anderson, n.d.). The increased number of false alarms by the elderly group raises concern because this means they are confident that they perceive accurately even when in error. This could have happened because the elderly participants experienced diminished processing capabilities due to their aging.

The music note proved to be an effective stimulus in identifying duration discrimination differences in young and elderly participants. This means that it could be used for Central Auditory Processing Disorder (CAPD) testing in the future. 


\section{Limitations and Implications}

One elderly adult participant with a $48 \mathrm{dBHL}$ received the stimulus at $60 \mathrm{~dB}$ instead of 50dB like the other participants. Also, the definition of "music experience" should have been better defined by stating a specific type of experience with voice or instrument to qualify as musically inclined.

Later, this study could be repeated with more independent or dependent variables, like longer standard durations to make processing more difficult and producing multiple sounds in one stimulus. This study could continue to build by changing the frequencies and/or making the stimulus a melodic sequence. Including other age groups, such as a middle-aged group, or analyzing the elderly age group’s results further could even show more detailed results of duration discrimination abilities as people age. Other populations as participants could also prove significant results, which would further the credibility for this type of test to be included in CAPD testing. 


\section{Conclusion}

This study has aimed to test, record, and interpret the results of duration discrimination across age groups. Using this methodology, age was found to have an effect on duration discrimination and the elderly adults performed more poorly than the young adults. Not only did the elderly participants score lower percent correct on the test, they also were more often confident that an errant response was accurate. This music stimulus could be used more frequently as a nonspeech stimulus for a central auditory processing disorder examination. In every day speech, duration discrimination is used to identify stressing in syllables. By testing across different age groups, this study supports the use of a music note stimulus to identify auditory processing disorders. The stimulus could be used in an auditory testing battery to identify CAPD. Since the data for this study showed significant and insignificant results, further studies should be done in the future to accumulate more data on the topic. 


\section{References}

Abel, S. M. (1972). Discrimination of temporal gaps. The Journal of the Acoustical Society of America, 52(2), 519-525.

Abel, S. M. (1972). Duration discrimination of noise and tone bursts. The Journal of the Acoustical Society of America, 51(4), 1219-1223.

Berkowitz, A., and Hochberg, I. (1971). Self-assessment of hearing handicap in the aged. Arch. Otolaryngol., 93, 25-28.

CHABA. (1988). Speech understanding and aging. The Journal of the Acoustical Society of America, 83(3), 859-895.

Cyr, A., \& Anderson, N. D. (n.d). Updating misconceptions: Effects of age and confidence. Psychonomic Bulletin \& Review, 20(3), 574-580.

Etchemendy, P. E., Eguia, M. C., \& Mesz, B. B. (2014). Principal pitch of frequencymodulated tones with asymmetrical modulation waveform: a comparison of models. The Journal of the Acoustical Society of America, 135(3), 1344-1355.

Freigang, C., Schmidt, L., Wagner, J., Eckardt, R., Steinhagen-Thiessen, E., Ernst, A., \& Rübsamen, R. (2011). Evaluation of central auditory discrimination abilities in older adults. Frontiers in Aging Neuroscience, 3(6), 1-11.

Gelfand, Stanley A. (1998). Hearing: An introduction to psychological and physiological acoustics. Theory of Signal Detection, 271-280. 
Glorig, A., and Nixon, J. (1962). Hearing loss as a function of age. Laryngoscope, 72, 1596-1610.

Grassi, M., \& Borella, E. (2013). The role of auditory abilities in basic mechanisms of cognition in older adults. Frontiers in Aging Neuroscience, 5(59), 1-9.

Güçlü, B., Sevinc, E., \& Canbeyli, R. (2011). Duration discrimination by musicians and nonmusicians. Psychological Reports, 108(3), 675-687.

Koelsch, Stefan. (2012). Brain and Music. Chichester, West Sussex: Wiley-Blackwell.

McMahon, O. (1979). The relationship of music discrimination training to reading and associated auditory skills. Bulletin of the Council for Research in Music Education, 59, 68-72.

Peter, V., McArthur, G., \& Thompson, W. F. (2012). Discrimination of stress in speech and music: A mismatch negativity (MMN) study. Psychophysiology, 49(12), 15901600.

Sound Forge (Version 9) [Computer software]. Middleton, WI: Sony Creative Software, Inc.

White, B. W. (1954). Visual and auditory closure. Journal of Experimental Psychology, 48(4), 234-240. 


\section{Appendix}

The following are official announcements of my research printed in four church bulletins and in the USM Mailout (campus email listserv).Some churches gave their members a copy of my study’s cover letter. The cover letter was also given to every participant at the time of testing.

\section{Research Volunteers Needed} USM senior student, Rachael Luckett, needs volunteers for her honors research. Volunteers of ages 18-30 and 65-90 are needed. A maximum of 30 minutes would be spent doing a hearing discrimination test with Rachael in the Speech and Hearing Clinic at USM. There are no risks associated with this project and it has been IRB approved. Please contact Rachael Luckett at Rachael.1uckett@eagles.usm.edu or 662-820-3681 for more information.

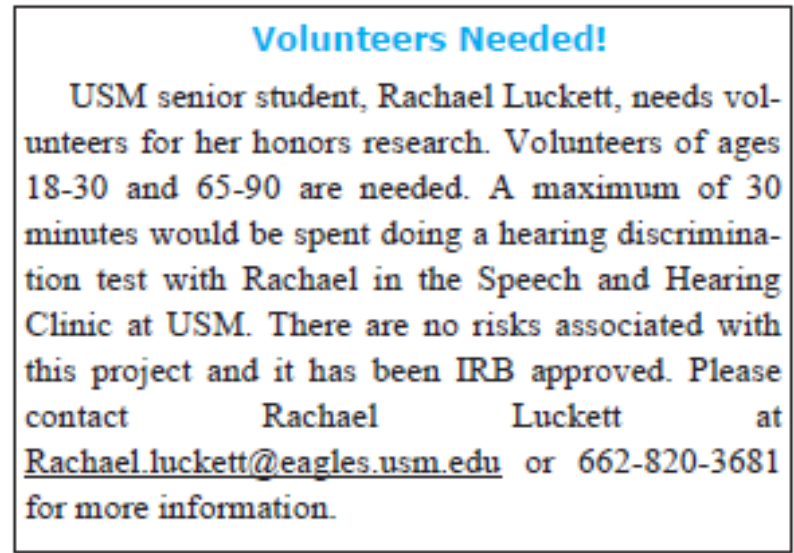

\section{Participants Age 18-30 and 65-90 Needed for Honors Thesis Research}

Senior Honors student, Rachael Luckett, needs volunteers for her thesis research. Volunteers of ages 1830 and $65-90$ are needed. A maximum of 30 minutes would be spent doing a hearing discrimination test with Rachael in the Speech and Hearing Clinic at USM.

There are no risks associated with this project and it has been IRB approved. Please contact Rachael Luckett at Rachael.luckett@eagles.usm.edu or 662-820-3681 for more information. 
To Whom It May Concem.

My name is Rachael Ludeett, and I am an undergraduate researcher within the Department of Speech and Hearing Sciences at the University of Southem Mississippi To better understand auditory discrinination. I am conducting research in USM's Audiology Clinic. The purpose of this study is to explose the relationship between aging and the ability to discriminate auditory durations using a musical note.

You will be asked to complete a questiomaire, a basic hearing screening, and the primary experiment while attending a session with me at the USM Audiology Clinic. Your total participation should take no longer than thisty $(30)$ minutes to complete. You will be asked about your current and previous hearing status and rusical training You will be asked what you hear during the hering screening and the primary experiment

This survey is completely volumtary and confidential. You will never be asked to provide a name or any other form of identification that would comect you with any particular data. If at any time while participating in the session you feel that you do not wish to continue, you can stop immadiately without any penalty, prejudice, or loss of benefits.

The experiment session will nead to be arranged prior to the session day. Per your convenience, the consent form will be the first page of the questiomaire. If you wish to participate in this project, then your signature will be required in order to indicate your consent for your participation. If you have any questions regarding this research project, please feel free to contact me at rachaelluckett/Qeagles. usmedu or Dr. Edward Goshorn at edward go shomagagles us medu.

[This project has been reviewed by the Human Subjects Protection Review Committee, which ensuses that research projects involving human subjects follow federal regulations. Any questions or concems about rights as a research subject should be directed to the chair of theInstitutional Review Board. The University of Southem Mississippi, 118 CoIlege Drive=5 116, Hattiesburg, MS 39406-0001, (601) 2665997.]

Thank you for your time and consideration of this request

Sincerely.

Rachael Luckett

Undergraduate Researcher

Department of Speech and Hearing Sciences

The University of Southem Mississippi 
The following pages contain examples of the testing instructions, consent form, questionnaire, audiogram, and subject response forms used during testing.

\section{PIANO NOTE DURATION DISCRIMINATION TEST}

\section{INSTRUCTIONS}

Listen for a pair of piano tones that are each about one second long. There is a brief pause of about one half second between them. Your task is to decide whether or not the tones are equal in duration. Some tone-pairs are equal in duration and some are not. After you hear a pair of tones, tell the examiner if you judge them to be equal in duration by saying "SAME". If you judge they are not equal in duration say "DIFFERENT". The tone-pairs are separated by about four seconds of silence. The first six pairs are for practice. The examiner will tell you after each practice-pair whether the pair is equal or different in duration. The test begins following two brief "beep" sounds. Again, listen for the tone-pairs and say "SAME" if you judge they are equal in duration and say "DIFFERENT" if they are not.

After making your judgment of "same" or "different" duration of a tone-pair, tell the examiner whether or not you believe your response is accurate. If you are confident your response is accurate, say "YES," but if you are unsure of the accuracy of your response, say "NO". Then be ready to judge the next pair of piano notes. There are 100 pairs of piano notes to judge. Listen carefully and try to do the best you can.

If you are unsure of what to do at any time, ask the examiner for help. 


\section{Questionnaire}

$1^{\text {st }}$ stage-Consent:

Participant's name:

[Printed]

Consent is hereby given to participate in the research project entitled, "Aging and Auditory Duration Discrimination Using a Musical Note." All procedures and their purpose were explained in a letter by Rachael Luckett in affiliation with the Department of Speech and Hearing Sciences at the University of Southem Mississippi. Information was given regarding all benefits, risks, inconveniences, or discomforts that might be expected.

The opportunity to ask questions has been given through contacting the researcher through the contact information provided below. Participation in the project is completely voluntary, and participates may withdraw at any time without penalty, prejudice, or loss of benefits. All personal information is strictly confidential, and no names will be disclosed. Any new information that develops during the project will be provided if that information may affect the willingness to continue participation in the project.

Questions concerning the research, at any time during or after the project, should be directed to Rachael Luckett at rachael.luckett@eagles.usm.edu or Dr. Edward Goshorn at Edward.goshom Qusm.edu. [This project and consent form has been reviewed by the Human Subjects Protection Review Committee, which ensures that research projects involving human subjects follow federal regulations. Any question or concerns about rights as a research participant should be directed to the Chair of Institutional Review Board, The University of Southern Mississippi, 118 College Drive \#5116, Hattiesburg, MS 39406-0001,(601) 266-5997.

By signing and dating below, you hereby agree to the terms and conditions of this questionnaire and research method.

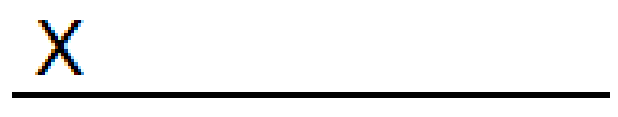


$2^{\text {^s }}$ stage - Questionnaire:

1. Subject $\#$ :

2. Age:

3. Sex:

4. Ethnicity:

5. Education (check all that apply): [ ]High school [ ]GED [ ]Some college

[ ]Associates [ ]Bachelors [ ]Masters [ ]Professional [ ]Doctorate

6. How many languages do you speak? List them.

7. Please list any musical training or background you have and how many years you have had it:

8. Have you had any previous hearing impairments? Please explain. 
'UNIVERSITY OF SOUTHERN MISSISSIPPI Audiology Clinic

Department of Speech and Hearing Sciences

118 College Drive \#5092

Hattiesburg, MS 39406

Phone: (601) 266-5232

Fax: (601) 266-5224
Client Name:

DOB:

Age

Address:

Examiner:

Supervisor:
Date:

Gender
FREQUENCY IN HERTZ

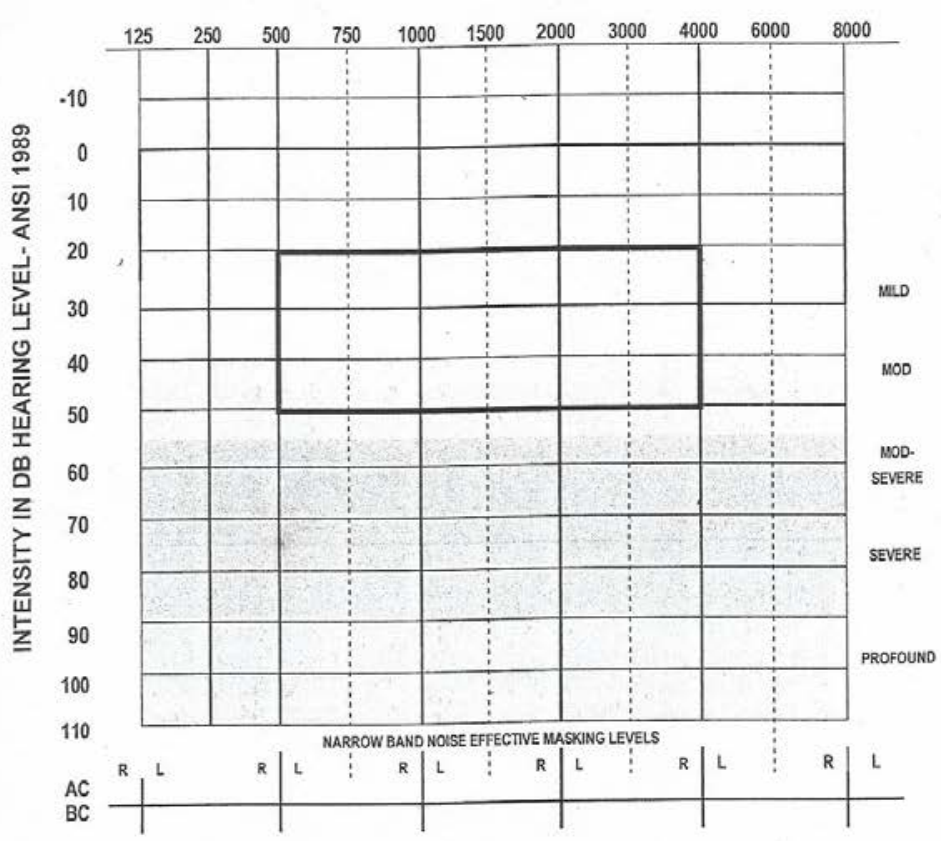

\begin{tabular}{|c|c|c|c|c|c|}
\hline \multicolumn{6}{|c|}{ TEST CONDITIONS } \\
\hline \multicolumn{3}{|c|}{ Audiometer } & & & \\
\hline \multicolumn{3}{|c|}{ Calibration date } & & & \\
\hline \multicolumn{3}{|c|}{ Reliability } & & & \\
\hline \multicolumn{3}{|c|}{ Response } & St & & COR \\
\hline \multicolumn{3}{|c|}{ Earphone } & \multicolumn{3}{|c|}{ Insert Circumaural } \\
\hline \multicolumn{6}{|c|}{ Audiogram Key } \\
\hline & $\mathbf{R}$ & $\mathrm{L}$ & \multirow{2}{*}{\multicolumn{3}{|c|}{ Unmasked }} \\
\hline \multirow[t]{2}{*}{ AC } & 0 & $\mathbf{x}$ & \multirow{2}{*}{\multicolumn{3}{|c|}{ Masked }} \\
\hline & $\Delta$ & $\square$ & & & \\
\hline \multirow[t]{5}{*}{$B C$} & $<$ & $>$ & \multicolumn{3}{|c|}{ Unmasked } \\
\hline & [ & ] & \multicolumn{3}{|c|}{ Masked } \\
\hline & $k$ & $y$ & \multicolumn{3}{|c|}{ No response } \\
\hline & \multicolumn{2}{|l|}{$\mathrm{S}$} & \multicolumn{3}{|c|}{ Soundfield } \\
\hline & \multicolumn{2}{|c|}{ A } & \multicolumn{3}{|c|}{ Aided } \\
\hline \multirow{4}{*}{$\begin{array}{l}\mathrm{P} \\
\mathrm{T} \\
\mathrm{A}\end{array}$} & & & - & R & SF \\
\hline & HF-AC & & & & \\
\hline & Sp-AC & & & & \\
\hline & $\mathrm{BC}$ & & & & \\
\hline
\end{tabular}

$\mathrm{R}$

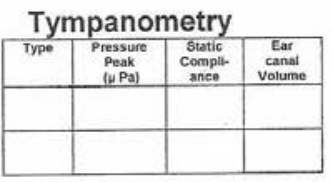

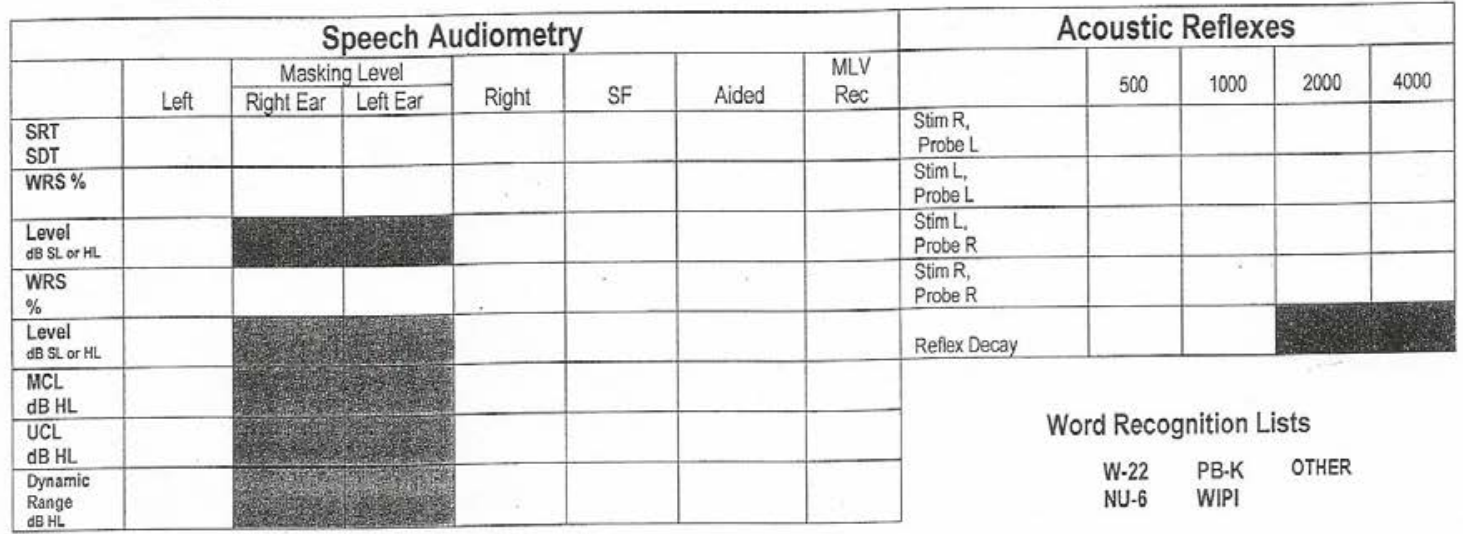

Comments: 
SUBJ:

DATE:

PIANO NOTE DURATION DISCRIMINATION SUBJECT'S RESPONSE SHEET

\begin{tabular}{|c|c|c|c|c|c|}
\hline & & & & SS'S RESP & \\
\hline ITEM \# & $\begin{array}{l}\text { TONE } 1 \\
\text { (msec) }\end{array}$ & $\begin{array}{l}\text { TONE } 2 \\
\text { (msec) }\end{array}$ & $\begin{array}{l}\text { CORR } \\
\text { RESP } \\
\text { (S/D) }\end{array}$ & (S/D) & $\begin{array}{c}\text { CONF } \\
\text { RATING } \\
(\mathrm{Y} / \mathrm{N})\end{array}$ \\
\hline PRACT1 & 1000 & 1000 & $S$ & & \\
\hline PRACT2 & 1000 & 1000 & $S$ & & \\
\hline PRACT3 & 1000 & 900 & D & & \\
\hline PRACT4 & 1000 & 900 & D & & \\
\hline PRACT5 & 1000 & 800 & D & & \\
\hline PRACT6 & 1000 & 800 & D & & \\
\hline 1 & 1000 & 1000 & $S$ & & \\
\hline 2 & 1000 & 800 & D & & \\
\hline 3 & 1000 & 1000 & $S$ & & \\
\hline 4 & 1000 & 1000 & $S$ & & \\
\hline 5 & 1000 & 1000 & $S$ & & \\
\hline 6 & 1000 & 1000 & $S$ & & \\
\hline 7 & 1000 & 900 & D & & \\
\hline 8 & 1000 & 1000 & $S$ & & \\
\hline 9 & 1000 & 1000 & $S$ & & \\
\hline 10 & 1000 & 900 & D & & \\
\hline 11 & 1000 & 900 & D & & \\
\hline 12 & 1000 & 900 & D & & \\
\hline 13 & 1000 & 800 & D & & \\
\hline 14 & 1000 & 1000 & $S$ & & \\
\hline 15 & 1000 & 1000 & $S$ & & \\
\hline 16 & 1000 & 1000 & $S$ & & \\
\hline 17 & 1000 & 900 & D & & \\
\hline 18 & 1000 & 800 & D & & \\
\hline 19 & 1000 & 1000 & $S$ & & \\
\hline 20 & 1000 & 900 & D & & \\
\hline 21 & 1000 & 900 & D & & \\
\hline 22 & 1000 & 1000 & $S$ & & \\
\hline 23 & 1000 & 1000 & $S$ & & \\
\hline 24 & 1000 & 800 & D & & \\
\hline 25 & 1000 & 1000 & $S$ & & \\
\hline 26 & 1000 & 800 & D & & \\
\hline 27 & 1000 & 900 & D & & \\
\hline 28 & 1000 & 900 & D & & \\
\hline 29 & 1000 & 800 & D & & \\
\hline 30 & 1000 & 1000 & $S$ & & \\
\hline 31 & 1000 & 1000 & $\$$ & & \\
\hline 32 & 1000 & 900 & D & & \\
\hline 33 & 1000 & 1000 & $S$ & & \\
\hline
\end{tabular}

EXAMINER:

PRESENTATION LEVEL:

03.17 .2014 
SUBJ:

PIANO NOTE DURATION DISCRIMINATION SUBJECT'S RESPONSE SHEET

DATE:

EXAMINER:

PRESENTATION LEVEL: DBHL

03.17.2014 
SUBJ:

DATE:

\begin{tabular}{|c|c|c|c|c|c|}
\hline 78 & 1000 & 800 & D & & \\
\hline 79 & 1000 & 1000 & S & & \\
\hline 80 & 1000 & 800 & D & & \\
\hline 81 & 1000 & 1000 & S & & \\
\hline 82 & 1000 & 800 & D & & \\
\hline 83 & 1000 & 900 & D & & \\
\hline 84 & 1000 & 800 & D & & \\
\hline 85 & 1000 & 900 & D & & \\
\hline 86 & 1000 & 1000 & S & & \\
\hline 87 & 1000 & 1000 & S & & \\
\hline 88 & 1000 & 1000 & S & & \\
\hline 89 & 1000 & 1000 & S & & \\
\hline 90 & 1000 & 800 & D & & \\
\hline 91 & 1000 & 900 & D & & \\
\hline 92 & 1000 & 1000 & S & & \\
\hline 93 & 1000 & 900 & D & & \\
\hline 94 & 1000 & 800 & D & & \\
\hline 95 & 1000 & 1000 & S & & \\
\hline 96 & 1000 & 800 & D & & \\
\hline 97 & 1000 & 900 & D & & \\
\hline 98 & 1000 & 1000 & S & & \\
\hline 99 & 1000 & 800 & D & & \\
\hline 100 & 1000 & 900 & D & & \\
\hline & & & & & \\
\hline
\end{tabular}

PIANO NOTE DURATION DISCRIMINATION SUBJECT'S RESPONSE SHEET
EXAMINER:

PRESENTATION LEVEL:

03.17.2014 


\section{fi \\ 1) THE UNIVERSITY OF \\ जinIII SOUTHERN MISSISSIPPI}

\section{INSTITUTIONAL REVIEW BOARD}

118 College Drive \#5147 | Hattiesburg, MS 39406-0001

Phone: 601.266 .5997 | Fax: 601.266 .4377 | www.usm.edu/research/institutional.review.board

\section{NOTICE OF COMMITTEE ACTION}

The project has been reviewed by The University of Southern Mississippi Institutional Review Board in accordance with Federal Drug Administration regulations (21 CFR 26, 111), Department of Health and Human Services (45 CFR Part 46), and university guidelines to ensure adherence to the following criteria:

- The risks to subjects are minimized.

- The risks to subjects are reasonable in relation to the anticipated benefits.

- The selection of subjects is equitable.

- Informed consent is adequate and appropriately documented.

- Where appropriate, the research plan makes adequate provisions for monitoring the data collected to ensure the safety of the subjects.

- Where appropriate, there are adequate provisions to protect the privacy of subjects and to maintain the confidentiality of all data.

- Appropriate additional safeguards have been included to protect vulnerable subjects.

- Any unanticipated, serious, or continuing problems encountered regarding risks to subjects must be reported immediately, but not later than 10 days following the event. This should be reported to the IRB Office via the "Adverse Effect Report Form".

- If approved, the maximum period of approval is limited to twelve months.

Projects that exceed this period must submit an application for renewal or continuation.

PROTOCOL NUMBER: 14090903

PROJECT TITLE: Aging and Auditory Duration Discrimination using Musical Notes PROJECT TYPE: New Project

RESEARCHER(S): Rachael Luckett

COLLEGE/DIVISION: College of Health

DEPARTMENT: Speech and Hearing Sciences

FUNDING AGENCY/SPONSOR: N/A

IRB COMMITTEE ACTION: Exempt Review Approval

PERIOD OF APPROVAL: $12 / 18 / 2014$ to $12 / 17 / 2015$

Lawrence A. Hosman, Ph.D.

Institutional Review Board 